\title{
Public health for paediatricians: How can behavioural economics help to make paediatric practice more effective?
}

\author{
Rakhee Shah, Ann Hagell
}

Association for Young People's Health, London, UK

\section{Correspondence to}

Dr Rakhee Shah, Association for Young People's Health, 32-36 Loman Street, London SE10EH, UK; rakhee@ youngpeopleshealth.org.uk

Received 31 May 2018 Accepted 18 August 2018 Published Online First 15 September 2018

\section{Check for updates}

(c) Author(s) (or their employer(s)) 2019. No commercial re-use. See rights and permissions. Published by BMJ.

To cite: Shah R, Hagell A. Arch Dis Child Educ Pract Ed 2019;104:146-149.

\begin{abstract}
Understanding the principles of behavioural economics is important for paediatricians

because behavioural economics offers ideas to help improve the quality of paediatric care. It can also be used to inform health interventions/policy at a population level. This paper summarises key behavioural economic concepts such as bounded rationality, bounded willpower and social influence, explaining how they can be used to shape healthy behaviours in children and adolescents. Case studies of interventions that have used behavioural economics principles (sometimes called 'nudge theory') are provided.
\end{abstract}

\section{THE CHALLENGE OF CHANGING HEALTH BEHAVIOURS}

There is currently an increasing focus on teaching clinicians about 'behaviour change theory' to provide them with a better understanding of what shapes human behaviour. This understanding is key to designing more effective interventions to improve child health and health services.

Unhealthy behaviours make a significant contribution to the global burden of non-communicable diseases. With 5\% of 15 year-olds reporting regular cigarette smoking, one in five 11-15 yearolds being obese and only $9 \%$ of girls and $17 \%$ of boys aged $13-15$ achieving 1 hour of exercise a day, unhealthy behaviours among children and young people in the UK have proven difficult to change. ${ }^{1}$ Unhealthy behaviours initiated in childhood and adolescence often continue into later life, making it a priority to try and alter these behaviours earlier on. In addition, we have seen rising pressures observed on paediatric emergency departments over recent years, with children and young people increasingly presenting with minor illnesses. ${ }^{2}$ Children and young people can also be difficult to engage in longer term, secondary care.

\section{WHAT IS BEHAVIOURAL ECONOMICS?}

The study of economics requires an understanding of how and why humans make decisions and therefore helps us to understand behaviour that affects health. It is important to note that achieving 'good health' may not be the sole objective of behaviour. It has been suggested that human behaviour is shaped by two systems. ${ }^{3}$ The first is a reflective goal-oriented system driven by our intentions, which requires mental capacity and time. The second system is an involuntary system which is driven by individual psychological processes such as emotions, social influences, mental short cuts and habits that require little or no thinking. These individual psychological processes are also known as cognitive biases. Cognitive biases are essentially ways of thinking that are not entirely rational.

Classical economic theory presumes that human behaviour is rational and based on the first system; that people coolly weigh up the pros and cons of different behaviours and choose the option of maximum personal benefit. However, it transpires instead that human behaviour is more commonly based on the second system, and therefore is not as rational as we imagined. As a result, some quite straightforward public health interventions simply do not seem to work.

Cognitive biases influence decision-making by both patients and healthcare practitioners, and can lead to unhealthy behaviours, inappropriate health-seeking behaviour ${ }^{4}$ and to illogical decisions that can affect the quality of clinical care provided. ${ }^{5}$ 
Understanding these biases thus might be useful in improving health. This is where behavioural economics comes in. Behavioural economics seeks to understand the influence of the cognitive biases driving the second, irrational system of human behaviour and uses the knowledge of these biases to 'nudge' behaviour into better outcomes for the individual or society. ${ }^{67}$

\section{SOME KEY IDEAS IN BEHAVIOURAL ECONOMICS}

There are three main groups of biases that are relevant for understanding health behaviours in children and young people, and also in their families and practitioners.

\section{Mental short cuts}

Also known as 'bounded rationality', this means that people often use rules of thumb and opt for the decisions that are the easiest to make. Status quo bias, anchoring heuristics and framing effects are examples of bounded rationality:

- Status quo bias: The line of least resistance is to do nothing and maintain the status quo. The most prominent example of this is the rise in rates of organ donation in countries where the default option was changed from not being an organ donor to being an organ donor. ${ }^{8}$

- Anchoring heuristics: The first piece of information people receive on a topic acts as an anchor or a baseline, so it is very important in providing a base for subsequent behaviour. For example, the size of plates and glasses has increased in recent years. If people are given a large plate, they will help themselves to a larger portion, ${ }^{9}$ setting a new 'norm' for the family. Counselling parents of overweight children in clinic to reduce portion size by reducing the size of tableware can be effective. ${ }^{9}$

- Framing effects: People react differently to health information depending on whether it is presented as a loss or a gain. For example, there is some evidence that parents may be more persuaded to have their children immunised if the losses of not doing so are emphasised. ${ }^{10}$

\section{Bounded willpower}

People do not always make decisions that are in their long-term self-interest; their willpower is not infinite. Two examples are 'present bias' and 'hyperbolic discounting"7:

- Present bias: People often disproportionately value the present. Making the long-term implications of a behaviour more immediate may help promote healthier behaviour. For example, in one study, showing young people the ultraviolet damage done by tanning booths improved intentions to use sun protection, by bringing the cost of the unhealthy behaviour nearer to the present. ${ }^{11}$

- Hyperbolic discounting: People are biased to choose smaller sooner rewards when compared with larger later rewards. There is some evidence that hyperbolic discounting is more common in adolescence ${ }^{12}$ and this may explain their increased impulsivity in risktaking behaviour such as smoking, or excessive alcohol consumption.

\section{Social norms}

Correcting misperceptions about the behaviours of others may promote healthier behaviour. For example, Arizona University used posters and flyers to correct misperceptions on how many college students actually drank alcohol. By promoting the norm that only a minority of students drank excessively, they reduced the pressure on students to consume alcohol, leading to a decrease in binge drinking. ${ }^{13}$ A similar exercise has been done to reduce inappropriate prescription of antibiotics in order to tackle antimicrobial resistance. The highest prescribers of antibiotics were informed by letter that they were prescribing antibiotics at a higher rate than $80 \%$ of their peers in England. Over 6 months this resulted in an average decrease of antibiotic prescriptions. ${ }^{14}$

\section{WHY IS BEHAVIOURAL ECONOMICS RELEVANT FOR PRACTISING PAEDIATRICIANS?}

Sensible parents and young people can make decisions which are not always in the best interests of their longer term health, such as refusing vaccinations. An understanding of behavioural economic techniques can be used by paediatricians to influence decision-making by parents and young people and to develop effective interventions that promote healthy behaviours among children and young people. Having an understanding of behavioural economic techniques can also help us shape the behaviour of healthcare professionals, improving both clinical outcomes and the quality of care provided.

There are a number of ways in which the concepts could be applied to paediatrics. These relate to the healthcare environment, methods of communicating with patients, the ways in which information is presented, other elements of the medical consultation and choice of different interventions. For example:

- By framing the consultation in certain ways paediatricians can use the knowledge of mental short cuts to help parents and young people make decisions that improve their child's or their own welfare without limiting their choices (box 1).

- Changing the physical environmentcan be a way of shaping physical behaviour, including, for example, altering the way food is presented to consumers in shops and canteen settings to encourage healthy eating in shops and canteen settings (box 2). This could be extended into the hospital environment.

- Well-timed and phrased remindersthrough text messages, for example, in box 3 , to patients and families could 'nudge' them into attending appointments and reducing wastage.

- Sharing information about social norms can promote healthy behaviour among patients and can also reduce undesirable variations in clinical paediatric practice.

- Using knowledge of mental short cuts used by staff can help develop quality improvement projects. For example, the inpatient visual colour-coded paediatric emergency warning score charts can 'nudge' practitioners to identify a deteriorating child or young person earlier if 


\section{Box 1 Framing a medical consultation vignette}

\section{Consultation A: A loss frame}

Sam is a 14-month-old boy who has attended the accident and emergency department with a runny nose. As the paediatric doctor you discover when taking a routine history that he has not had his measles, mumps and rubella (MMR) vaccination. His mother reports that she has chosen to not vaccinate Sam because she is concerned that the MMR vaccine causes autism. In this situation, alongside debunking the false claims that the MMR vaccine causes autism, you could choose to frame the information around the MMR vaccine as a loss or a gain. For example, emphasising the potential damage to hearing or even fertility if Sam developed mumps to Sam's mother would be framing the lack of vaccination as a loss. There is some evidence that parents may be more persuaded to have their children immunised if the losses of not doing so are emphasised. ${ }^{9}$

\section{Consultation B: A gain frame}

Tamara is a 15-year-old girl who is attending outpatient clinic for a review following an admission for a pneumonia. On questioning you find out that Tamara smokes around two cigarettes a day. Once again you have a choice to frame the health information about smoking as a gain or a loss. As the paediatric consultant you choose to present the information on smoking cessation as a gain which can be more effective when promoting health. You advise Tamara that if she quits smoking she is going to have healthier lungs and as smoking is an expensive habit she will have more money to spend on other activities she enjoys.

observations are abnormal and plot in the yellow zone instead of the green zone.

- Changing the status quo, for example, to 'out opt' for seasonal influenza vaccinations for paediatric healthcare workers may increase vaccination rates.

\section{CRITICISMS OF A BEHAVIOURAL ECONOMICS APPROACH}

Behavioural economics and 'nudges' are not without their criticisms. Some argue that interventions based

\section{Box 2 Nudging food choices in a retail}

environment

Confectionary at checkouts in supermarkets is strategically placed at the eye level of children to particularly target this age group. Several adaptations to the retail environment have been developed and trialled to try and increase consumption of healthier food in supermarkets. One such example is substituting chocolates and sweets at some supermarket checkouts with healthier snacks such as cereal bars and fruit, in order to reduce impulsive purchase of unhealthy foods. Four major supermarkets in the UK have now banned confectionary at their checkouts. A field study at a train station ${ }^{21}$ and longitudinal studies in Europe $\mathrm{e}^{22}$ have shown that repositioning healthier food options at checkout counters increased purchases of healthier food options. ${ }^{21} 22$
Box 3 Nudges to increase hospital attendance and reduce wastage

Missed hospital appointments are a major cause of health system inefficiency and cost the National Health Service (NHS) in England $\mathrm{f} 1$ billion last year (NHS England). An intervention that aimed to increase hospital attendance to outpatient clinic by attracting attention to health information more effectively included altering the content of text message reminders of upcoming appointments. A $25 \%$ reduction in 'did-not attend' outcomes was achieved by stating the exact cost to the health system of a missed appointment, which was found to be the most effective method of communication to nudge people to attend their appointments. ${ }^{20}$ This type of innovative intervention to reduce missed appointment could be incorporated into text messages and appointment letters sent to parents.

on behavioural economic concepts put too much emphasis on individual behaviour and on the downstream determinants of ill health. ${ }^{15}$ There have been concerns about the ethics around 'nudges' and their impact on individual autonomy. It has been argued that the behavioural economics approach is too paternalistic and that although these strategies may change behaviour in a modest way, they cannot change more complex social problems such as child abuse, for example. ${ }^{15}$ Nudge techniques can however be used alongside other public health strategies and do not attempt to replace strategies to reduce health/social inequality.

Recent arguments suggest an ethical justification for nudging towards healthier behaviours in paediatrics. Nudging - if done correctly and ethicallyshould alter the environment in a way that does not take away parental choice but enables families to make decisions that are in the child's interests, especially when the recommended intervention is proven to be of a high benefit individually. ${ }^{16}$ Children and families in paediatric care are likely to be in a state of stress, affecting their ability to process information. Aggarwal et $\mathrm{al}^{17}$ have argued that understanding how this works and using that knowledge to help patients make the right decisions is a justifiable way of restoring their autonomy, not a way of taking it away. It is also possible to argue that the population is being constantly manipulated by the 'nudge' techniques of advertising and sales and so using these techniques transparently within healthcare is a way to redress the balance in favour of positive health outcomes. The issue is not so much whether we use our understanding of behavioural economics to inform practice, but how we do so in a way that is transparent and responsible. More evidence is needed on the effectiveness of interventions designed specifically for children and young people. 


\section{CONCLUSIONS}

A real understanding of the reasons why people make certain decisions aids healthcare professionals to change unhealthy behaviours among children and young people. This is particularly important as certain behaviour-related child health outcomes remain poor-the number of severely obese children in England at a record high ${ }^{18}$ and the rates of vaccination uptake are still not sufficient enough to meet the levels required for herd immunity. ${ }^{19}$ It is clear that the concepts of behavioural economics have important implications for quality improvement initiatives aiming to change physician behaviour and patient health-seeking behaviour.

\section{Glossary}

Anchoring heuristic: The first piece of information that people receive on a topic acts as an anchor or a baseline, so it is very important in providing a starting point for subsequent behaviour.

Bounded willpower: People do not always make decisions that are in their long-term self-interest; their willpower is not infinite and they can 'give up' in favour of other options. Two examples are 'present bias' and 'hyperbolic discounting'. Cognitive bias: Individual psychological processes such as emotions, social influences, mental short cuts and habits can get in the way of rational decision-making, creating a 'bias'. Hyperbolic discounting: People are biased to choose smaller sooner rewards when compared with larger later rewards. Framing effects: people react differently to health information depending on whether it is presented as a loss or a gain. Present bias: People often disproportionately value the present. Nudges: Nudge theory suggests that we need to alter environments in which choices are made, in order to 'nudge' people towards healthier behaviours. ${ }^{6}$

Status quo bias: The line of least resistance is to do nothing and maintain the status quo. ${ }^{20}$

Contributors RS and $\mathrm{AH}$ jointly contributed to the conception, design and drafting of the manuscript.

Competing interests None declared.

Provenance and peer review Commissioned; externally peer reviewed.

\section{REFERENCES}

1 Hagell A, Shah R, Coleman J. Key Data on Young People 2017. London, 2017. http://www.youngpeopleshealth.org.uk/keydata-on-young-people.

2 Keeble E, Kossarova L, 2017. Focus on: Emergency hospital care for children and young people https://www.nuffieldtrust. org.uk/research/focus-on-emergency-hospital-care-for-childrenand-young-people (cited 2018 Apr 18).

3 Strack F, Deutsch R. Reflective and impulsive determinants of social behavior. Pers Soc Psychol Rev 2004;8:220-47.

4 Perry C, Chhatralia K, Damesick D, et al, 2015. Behavioural insights in health care Nudging to reduce inefficiency and waste https://www.health.org.uk/sites/health/files/BehaviouralI nsightsInHealthCare.pdf (cited 2018 Apr 12).
5 Luoto J, Carman KG, 2014. Behavioral economics guidelines with applications for health interventions https://publications. iadb.org/bitstream/handle/11319/6503/Behavioral_economics guidelines_with_applications_for_health_interventions.pdf? sequence $=18$ isAllowed $=$ y (cited 2018 Apr 11).

6 Thaler RH, Sunstein CR. Nudge: improving decisions about health, wealth and happiness: Penguin Books, 2009:305.

7 Thorgeirsson T, Kawachi I. Behavioral economics: merging psychology and economics for lifestyle interventions. Am J Prev Med 2013;44:185-9.

8 Rice T. The behavioral economics of health and health care. Annu Rev Public Health 2013;34:431-47.

9 Marteau TM, Hollands GJ, Shemilt I, et al. Downsizing: policy options to reduce portion sizes to help tackle obesity. BMJ 2015;351:h5863.

10 O'Keefe DJ, Nan X. The relative persuasiveness of gain- and loss-framed messages for promoting vaccination: a metaanalytic review. Health Commun 2012;27:776-83.

11 Mahler HI, Kulik JA, Harrell J, et al. Effects of UV photographs, photoaging information, and use of sunless tanning lotion on sun protection behaviors. Arch Dermatol 2005;141:373-80.

12 Huang Y, Hu P, Li X. Undervaluing delayed rewards explains adolescents' impulsivity in inter-temporal choice: an ERP study. Sci Rep 2017;7:42631.

13 Johannessen K, Collins C, Glider P, et al. The University of Arizona's campus health social norms media campaign. The social norms approach to preventing school and college age substance abuse: A handbook for educators, counselors, and clinicians, 1999:65-82.

14 Hallsworth M, Chadborn T, Sallis A, et al. Provision of social norm feedback to high prescribers of antibiotics in general practice: a pragmatic national randomised controlled trial. Lancet 2016;387:1743-52.

15 Bonell C, McKee M, Fletcher A, et al. One nudge forward, two steps back. BMJ 2011;342:d401.

16 Blumenthal-Barby J, Opel DJ. Nudge or grudge? choice architecture and parental decision-making. Hastings Cent Rep 2018;48:33-9.

17 Aggarwal A, Davies J, Sullivan R. "Nudge" in the clinical consultation--an acceptable form of medical paternalism? BMC Med Ethics 2014;15:31.

18 England PH. Child obesity and excess weight: small area level data. UK, 2018. https://www.gov.uk/government/statistics/ child-obesity-and-excess-weight-small-area-level-data. (cited 2018 Jul 29).

19 WHO-UNICEF, 2016. WHO-UNICEF estimates of DTP3 coverage http://apps.who.int/immunization_monitoring/ globalsummary/timeseries/tswucoveragedtp3.html (cited 2018 Mar 20).

20 Hallsworth M, Berry D, Sanders M, et al. Stating appointment costs in sms reminders reduces missed hospital appointments: findings from two randomised controlled trials. PLoS One 2015;10:e0137306.

21 Kroese FM, Marchiori DR, de Ridder DT. Nudging healthy food choices: a field experiment at the train station. J Public Health 2016;38:e133-e137.

22 Van Gestel LC, Kroese FM, De Ridder DTD. Nudging at the checkout counter - A longitudinal study of the effect of a food repositioning nudge on healthy food choice. Psychol Health 2018;33:800-9. 